\title{
PTK1, a Mitogen-Activated-Protein Kinase Gene, Is Required for Conidiation, Appressorium Formation, and Pathogenicity of Pyrenophora teres on Barley
}

\author{
M. Carmen Ruiz-Roldán, Frank J. Maier, and Wilhelm Schäfer \\ Institute of General Botany, Department of Molecular Phytopathology and Genetics (AMP III), University of \\ Hamburg, Ohnhorststr. 18, D-22609 Hamburg, Germany \\ Accepted 28 October 2000.
}

\begin{abstract}
Mitogen-activated protein kinases (MAPKs) are a group of protein kinases that execute a wide variety of roles in cellular signal transduction pathways such as osmoregulation, cell wall biosynthesis, growth, and differentiation. A polymerase chain reaction (PCR) with degenerate primers based on conserved regions of known MAPKs was used to clone the MAPK gene PTK1 from the leaf pathogen $P y$ renophora teres (anamorph Drechslera teres), the causal agent of net blotch of barley (Hordeum vulgare L.). The predicted amino acid sequence shows high homology with MAPKs from other phytopathogenic fungi. The gene is present in the genome as a single copy. PTK1 is expressed during in vitro growth on complete medium, under conidiation-inducing conditions and during infection of barley leaves, as shown by reverse transcription-PCR studies. In order to assess the role of PTK1 in the life cycle of $P$. teres, targeted gene disruption was conducted. Mutants carrying an interrupted copy of the gene were deficient in conidiation, did not form appressoria on glass surfaces or on barley leaves, lost their ability to infect barley leaves, and could not colonize host tissues following artificial wounding.
\end{abstract}

Net blotch caused by the leaf pathogen Pyrenophora teres Drechs. (anamorph Drechslera teres) is one of the most economically devastating diseases of cultivated barley (Hordeum vulgare L.) (Weiland et al. 1999). Barley lines range from being highly resistant to highly susceptible to this pathogen, which is a highly variable organism that includes several virulence types (Douiyssi et al. 1998; Harrabi and Kamel 1990; Robinson and Jalli 1996; Steffenson and Webster 1992a). Nevertheless, little is known about the fungal genes that condition pathogenicity or cause the various observed pathotypes. We initiated molecular genetic studies of this pathogen to define genes responsible for attachment, penetration, and pathogenic growth.

$P$. teres produces asexual spores, called conidia, which are dispersed in moist air and attach tightly to the barley leaf sur-

Corresponding author: W. Schäfer

E-mail: schaefer@botanik.uni-hamburg.de

Nucleotide and amino acid sequence data were deposited in the GenBank database as accession no. AF272831. face, thus starting the infection cycle. Under high-moisture conditions, a conidium produces a germ tube that grows and differentiates a specialized infection structure called appressorium. After hyphal penetration of an epidermal cell, the fungus develops intracellular infection vesicles that may act like haustoria. After breaching the epidermal cell layer, the fungus grows exclusively in the apoplast of the mesophyll tissue (Keon and Hargreaves 1983). Eventually a lesion develops and, under conditions of high humidity, $P$. teres sporulates and releases more conidia to reinitiate the infection cycle.

In many fungal pathogens, development of penetration structures is triggered by the perception of physical and/or chemical signals from the plant surface (Gilbert and Dean 1996; Hoch et al. 1987; Lee and Dean 1994; Podila et al. 1993; Uchiyama and Okuyama 1990). Thus, signal transduction pathways in filamentous fungal cells are likely to be critical to the establishment of disease. Molecular genetic analysis of several fungal pathogens has demonstrated that mitogenactivated protein kinase (MAPK) signal transduction pathways play important roles in pathogenesis (Lev et al. 1999; Mayorga and Gold 1999; Müller et al. 1999; Takano et al. 2000, Xu and Hamer 1996; Xu et al. 1998; Zheng et al. 2000). MAPKs are a group of protein kinases that execute a wide variety of roles in other cellular signal transduction pathways such as osmoregulation, cell wall biosynthesis, growth, and differentiation (Brewster et al. 1993; Courchesne et al. 1989; Elion et al. 1990; Krisak et al. 1994). The functions of the various cloned MAPK genes in fungal life cycles seem to differ from one pathogen to the other (Table 1). Therefore, we assessed the impact of MAPK pathways from $P$. teres on its life cycle.

\section{RESULTS}

Isolation of the MAPK gene PTK1.

A nested-primer strategy was used to amplify wild-type genomic DNA. Four degenerate oligonucleotides were designed from conserved amino acid regions of MAPKs in other organisms (see below). After a first round of polymerase chain reaction (PCR) amplification with primers 2 and 4 (located on domains I and VIII, respectively), a nested PCR amplification was performed with primers 1 and 3 (located on domains VIII and II, respectively). Out of the two major PCR products generated (478 and $100 \mathrm{bp}$ ), the 478 -bp product matched the size 
expected for a segment between regions II and VIII of known protein kinases (Hanks and Quinn 1991; data not shown). Sequence analysis of this PCR fragment revealed a significant similarity to known MAPK genes. The 100-bp PCR product was not considered because of its small size.

Three positive clones were isolated following screening of a $\lambda$ EMBL3 library of genomic DNA of $P$. teres strain $15 \mathrm{~A}$ with the 478-bp PCR fragment as a probe. The three clones corresponded to the same genomic region, as deduced from restriction analysis. A 5.5-kb HindIII fragment that hybridized to the probe was subcloned into pBlueScript II KS+ (Stratagene, La Jolla, CA, U.S.A.). The resulting plasmid was named pPTK1$5.5 \mathrm{H}$. The nucleotide sequence of a $3.2-\mathrm{kb}$ region was determined. It contained an open reading frame with 1,265 bp coding a 352 amino acid polypeptide. Four introns of 55, 53, 51 , and $48 \mathrm{bp}$, respectively, were identified on the basis of the alignment with other MAPKs and the presence of conserved splice-site consensus sequences that are characteristic of filamentous fungi. The calculated molecular weight and $\mathrm{pI}$ of the encoded protein were 40.8 and $6.56 \mathrm{kDa}$, respectively. Comparisons with database entries demonstrated high similarities to other fungal MAPKs such as Chk1 of Cochliobolus heterostrophus with $98.9 \%$ identity (Lev et al. 1999); Bmp1 of Botrytis cinerea, $94.6 \%$ identity (Zheng et al. 2000); Cmk1 of Colletotrichum lagenarium, 92.9\% identity (Takano et al. 1999); Fsmapk of Nectria haematococca, $92.9 \%$ identity (Li et al. 1997); Pmk1 of Magnaporthe grisea, $91.8 \%$ identity (Xu and Hamer 1996); or Kpp2-Ubc3 of Ustilago maydis, 73.3\% identity (Mayorga and Gold 1999; Müller et al. 1999) (Fig. 1). We designated the corresponding $P$. teres gene PTK1. The deduced amino acid sequence of PTK1 contains all 11 conserved protein kinase domains (Hanks and Quinn 1991) in addition to the TEY sequence, a site for threonine-tyrosine phosphorylation required for kinase activation (Kültz 1998).
Southern blot analysis with several restriction enzymes indicated that the PTKl gene is present as a single copy in the genome of $P$. teres (data not shown).

\section{Expression of PTK1.}

PTK1 expression was studied by reverse transcription (RT)PCR during in vitro growth and during infection of barley leaves. Control reactions were performed with total RNA from uninfected leaves. Genomic DNA was used as template to compare sizes of the amplified fragments with or without introns (416 and $363 \mathrm{bp}$, respectively). The 363-bp amplification product of $P T K 1$ was obtained from RNA extracted from mycelium grown in complete medium $(\mathrm{CM})$ or from conidiophores and conidia produced on peanut leaves-oatmeal agar (POA) plates as well as during infection of barley leaves at all time points studied (Fig. 2). This amplified fragment was absent in the uninfected barley leaves. Cloning and sequencing of the bands confirmed that their sequences completely matched those of the genomic PTK1 clone, except for the absence of the intron.

\section{PTK1 is essential for pathogenicity and invasive growth in barley leaves.}

To determine the function of the PTK 1 gene in the life cycle of $P$. teres, a gene disruption strategy was conducted. A disruption vector, pKOptk1, was constructed containing a hygromycin B resistance gene cassette next to an internal 416-bp fragment of the PTK1 gene (Fig. 3A). pKOptk1 was linearized and introduced into the wild-type strain $15 \mathrm{~A}$ by a single crossover at the homologous locus, and transformants were selected on medium containing hygromycin B. Among 43 hygromycin-resistant transformants, nine contained an interrupted copy of the PTK1 gene, as shown by Southern blot analysis (Fig. 3B). Three of these ptk1 mutant strains con-

Table 1. The function of different mitogen-activated protein kinases (MAPKs) in fungal life cycles

\begin{tabular}{|c|c|c|c|}
\hline Organism & Gene & Function & Reference \\
\hline Aspergillus nidulans & $M P K A$ & Germination of conidia and polarized growth & Bussink and Osmani 1999 \\
\hline Botrytis cinerea & $B M P 1$ & Growth and pathogenicity on different plant species & Zheng et al. 2000 \\
\hline \multirow[t]{2}{*}{ Candida albicans } & HOG1 & Glycerol accumulation and virulence & San Jose et al. 1996; Alonso-Monge et al. 1999 \\
\hline & $M K C 1$ & Growth and morphogenesis under stress conditions & Navarro-Garcia et al. 1995 \\
\hline $\begin{array}{l}\text { Cochliobolus heterostro- } \\
\quad \text { phus }\end{array}$ & CHK1 & $\begin{array}{l}\text { Hyphal integrity, conidiation, appressorium formation } \\
\text { and pathogenicity on corn }\end{array}$ & Lev et al. 1999 \\
\hline $\begin{array}{l}\text { Colletotrichum lagenar- } \\
\text { ium }\end{array}$ & $C M K 1$ & $\begin{array}{l}\text { Pathogenicity, germination of conidia, appressorium } \\
\text { formation and invasive growth in cucumber }\end{array}$ & Takano et al. 2000 \\
\hline \multirow[t]{3}{*}{ Magnaporthe grisea } & PMK1 & Appressorium formation and pathogenicity on rice & $\mathrm{Xu}$ and Hamer 1996 \\
\hline & MPS1 & $\begin{array}{l}\text { Penetration peg formation, aerial hyphal growth and } \\
\text { conidiation }\end{array}$ & Xu et al. 1998 \\
\hline & OSM1 & $\begin{array}{l}\text { Response to hyperosmotic stress and cellular turgor } \\
\text { control }\end{array}$ & Dixon et al. 1999 \\
\hline Nectria haematococca & $F s M A P K$ & Unknown & Li et al. 1997 \\
\hline Ustilago maydis & $K P P 2-U B C 3$ & $\begin{array}{l}\text { Mating (pheromone signal) and pathogenic develo p- } \\
\text { ment on corn }\end{array}$ & Müller et al. 1999; Mayorga and Gold 1999 \\
\hline \multirow[t]{5}{*}{ Saccharomyces cerevisiae } & $S M K 1$ & Sporulation & Krisak et al. 1994 \\
\hline & HOG1 & Osmolyte synthesis in response to high osmolarity & Brewster et al. 1993 \\
\hline & FUS3 & Mating in response to pheromone signaling & Elion et al. 1990 \\
\hline & KSS1 & Filamentous growth & Courchesne et al. 1989 \\
\hline & $M P K 1$ & Cell wall remodeling in response to hypotonic shock & Torres et al. 1991 \\
\hline \multirow{2}{*}{$\begin{array}{l}\text { Schizosaccharomyces } \\
\quad \text { pombe }\end{array}$} & $P M K 1$ & Cell integrity & Toda et al. 1996 \\
\hline & $S P K 1$ & $\begin{array}{l}\text { Conjugation and meiosis in response to mating pher o- } \\
\text { mones }\end{array}$ & Gotoh et al. 1993 \\
\hline $\begin{array}{l}\text { Zygosaccharomyces } \\
\quad \text { rouxii }\end{array}$ & $\begin{array}{l}\mathrm{ZrHOG} 1 \\
\mathrm{ZrHOG} 2\end{array}$ & $\begin{array}{l}\text { Both involved in osmolyte synthesis in response to } \\
\text { high osmolarity }\end{array}$ & Iwaki et al. 1999 \\
\hline Pyrenophora teres & PTK1 & $\begin{array}{l}\text { Conidiation, appressorium formation, and pathogeni c- } \\
\text { ity on barley }\end{array}$ & This work \\
\hline
\end{tabular}


tained two copies of the vector integrated at the homologous locus, whereas the other six ptkl mutants contained a single copy of the disruption vector at the same position. Transcript analysis of the ptkl mutant strains was carried out by RT-PCR during in vitro growth on $\mathrm{CM}$ with the F7 and R8 PTK1 specific primers located at the $5^{\prime}$ and $3^{\prime}$ coding region of the gene, respectively. Control reactions were performed with total RNA from the wild-type strain. Genomic DNA from the wildtype strain was used as template to compare sizes of the amplified fragments, with or without introns (903 and $744 \mathrm{bp}$, respectively). The 744-bp amplification product of PTK1 was obtained from RNA from the wild-type strain, but it was absent when RNA from the ptkl mutant strains was used as template (data not shown), confirming that the gene was no longer active.

To determine whether $P T K 1$ is essential for pathogenicity on barley, we inoculated barley leaves with mycelial sus- pensions of all ptkl mutant strains and the wild type and one ectopic integration mutant as controls. Mycelium was used as inoculum instead of spores for proper comparisons between wild-type and ptkl mutant strains because mutants were not able to produce conidia, as shown below. Typical net blotch lesions were formed upon inoculation with wildtype mycelia as well as with the ectopic integration mutant (Fig. 4). No lesions were detected after inoculation with any of the ptk1 mutant strains, indicating that they had lost their pathogenicity. In order to test the ability of the ptkl mutants to colonize plant tissues, barley leaves were wounded by abrading the surface with sand before inoculation. Again, typical net blotch lesions were formed upon inoculation with wild-type or with the ectopic integration mutant, but no signs of disease were detected with any of the ptkl mutants (data not shown), indicating that they were not able to colonize the host tissue.

Ptk1
Cmk1
Fsmapk
Pmk1
Chk1
Bmp1
Kpp2/Ubc3

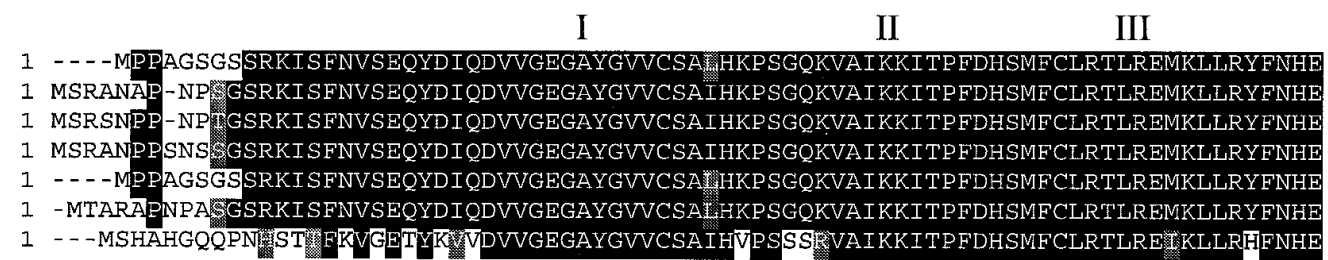

Ptk1
Cmk1
Fsmapk
Pmk1
Chk1
Bmp1
Kpp2 / Ubc3

IV $\mathrm{V}$

VI

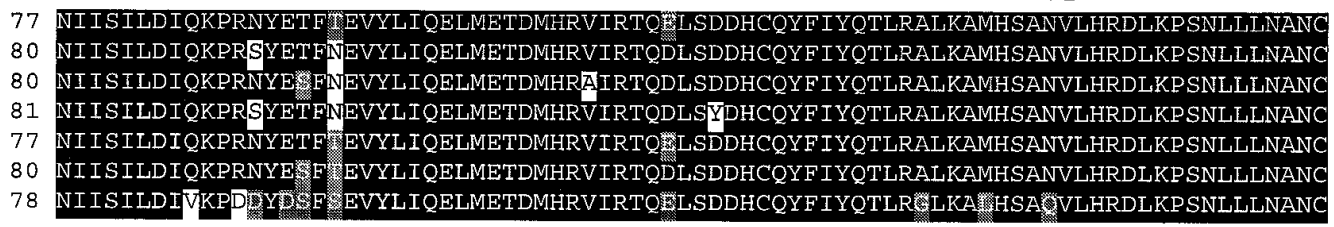

Ptk1
Cmk1
Fsmapk
Pmk1
Chk1
Bmp1
Kpp2/Ubc3

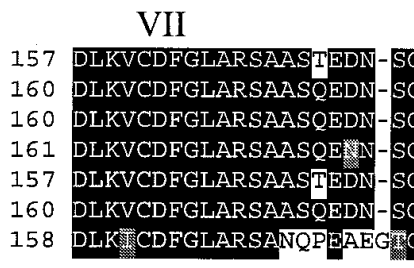
*** VIII

IX

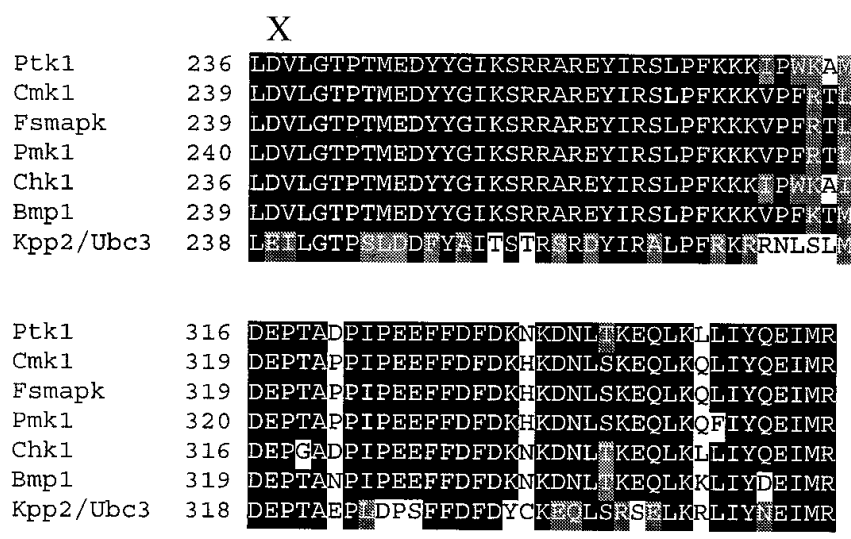

Fig. 1. Alignment of the predicted amino acid sequence encoded by the PTK1 gene to several mitogen-activated protein kinase (MAPKs). Alignment was performed with the CLUSTAL W 1.8 program (Thompson et al. 1994). Identical amino acids are indicated as white letters on black background. Similar residues are shown on a gray background. Gaps introduced for the alignment are indicated by hyphens. Protein kinase domains are indicated by Roman numerals (Hanks and Quinn 1991). TEY sequence required for kinase activation is marked by asterisks (Kültz 1998). GenBank accession nos. for $P$. teres Ptk1, C. heterostrophus Chk1, B. cinerea Bmp1, C. lagenarium Cmk1, N. haematococca Fsmapk, M. grisea Pmk1, and U. maydis Kpp2Ubc3 are AF272831, AF178977, AF205375, AF174649, U52963, U70134, and AF193614, respectively. 


\section{PTK1 is required for conidiation} and appressorium formation.

With the aim to determine at which infection step the ptkl mutants are affected, we studied their ability to produce conidia and to form appressoria in comparison to the wild-type and the ectopic integration mutant. Mycelium from the wildtype strain, the ectopic integration mutant, and the ptkl mutants were inoculated on POA plates, and conidium formation was checked 1 week later. Microscopic observation demonstrated that hyphae of the wild-type strain and ectopic integration mutant differentiated into conidiophores bearing conidia (Fig. 5A and C). In contrast, all ptkl mutants formed abnormally elongated conidiophores, three to four times longer than those produced by the wild type, and no conidia were detected at their tips (Fig. 5B and D). Hyphal tips of the wild-type strain and the ectopic integration mutant responded to the presence of a glass surface by swelling to form small appressoria (Fig. 5E). When mycelium from the ptkl mutants was inoculated on glass slides, the hyphae continued to grow and did not form any appressorium (Fig. 5F). The appressoriumdefective phenotype was not rescued in the ptkl mutants after the addition of exogenous cyclic AMP (cAMP) and no hyphae hooking or swelling was detected (data not shown). The same differences in appressorium formation were observed when barley leaves were inoculated with the wild-type strain and ptkl mutants (Fig. 5G to I). Wild-type hyphae responded to the presence of the barley leaf surface by growing toward the regions close to anticlinal cell walls where they formed appressoria and penetrated through the cuticle and the underlying cell wall into the epidermal cell (Fig. 5G and H). In contrast to the wild-type strain, hyphae from the ptkl mutants continued to grow on the leaf surface without developing any appressorium and no attempt to penetrate was observed (Fig. 5I). Colonies of $p t k 1$ strains, however, showed the same morphology as the wild-type strain on minimal medium (MM) or CM plates (data not shown), and no significant difference in growth rate between the wild-type and ptkl mutants was found during growth on those media or under osmotic stress conditions (data not shown). These results demonstrate that PTK1 gene is required for conidiophore differentiation and conidiation as well as for appressorium formation, but it is dispensable for vegetative growth.

\section{DISCUSSION}

In order to determine the roles of MAPK pathways in the life cycle of the ascomycete $P$. teres, we identified and characterized a MAPK gene of this fungus, $P T K 1$, which is highly homologous to other known fungal MAPKs. It is an extracellular, signal-regulated kinase belonging to the YERK1 subfamily of the MAPK family, whose main function in other eukaryotes is the transduction of extracellular signals (Kültz 1998).

Our results demonstrate that $P T K 1$ is dispensable for vegetative growth on MM or CM plates as well as under osmotic stress conditions because we did not detect any difference between the wild-type strain and the ptk1 mutants. In contrast, mutants in the MAPK gene CHK1 from the closely related fungal pathogen $C$. heterostrophus, which together with $P$. teres belongs to the former Helminthosporium spp., showed altered colony morphology with poorly developed aerial hy- phae and autolysis during vegetative growth (Lev et al. 1999). Moreover, the PTK1 transcripts were present in fungal mycelium during vegetative growth and in conidiophores and conidia as well as during the infection process, suggesting that the PTK1 gene may be expressed during all developmental stages tested. This indicates that regulatory mechanisms may occur at the posttranscriptional level, as widely described for protein kinase activities (Hunter 1995).

To discern the function of the PTK1 gene, we generated ptkl mutants and characterized their phenotypes. They form abnormally elongated conidiophores that do not bear any conidia. A defect in conidiation has been observed previously in $C$. heterostrophus chkl mutants, where no conidia were formed (Lev et al. 1999), and in cmkl mutants of C. lagenarium (Takano et al. 2000) or M. grisea mpsl mutants (Xu et al. 1998), where a significant reduction in conidiation has been described. These results are in contrast to those obtained in pmkl mutants of $M$. grisea (Xu and Hamer 1996) and B. cinerea bmpl mutants (Zheng et al. 2000), where conidiation was unaffected. An abnormal elongation of conidiophores in MAPK mutants has not been described.

ptkl mutants are unable to produce appressoria on glass surfaces or barley leaves. The involvement of MAPKs in appressorium formation has been described previously in the PMK1 gene of $M$. grisea (Xu and Hamer 1996) and its homologs, the CHK1 gene of C. heterostrophus (Lev et al. 1999) and the $C M K 1$ gene of $C$. lagenarium (Takano et al. 2000). In all of these cases, the inactivation of the corresponding MAPK gene led to an inability to produce appressoria. In M. grisea, it was proposed that the Pmk1 MAPK pathway works cooperatively with a cAMP pathway for appressorium formation because the addition of cAMP induced the early steps of appressorium formation in pmkl mutants, even though they failed to form mature appressoria (Xu and Hamer 1996). When exogenous cAMP was added to $p t k l$ mutants, however, it was not possible to induce the initiation of appressorium formation, suggesting that the PTK1 gene acts independently of a cAMP signaling pathway for appressorium formation.

ptkl mutants also lost their pathogenicity in barley leaves and were unable to grow invasively in barley plants, similar to pmkl mutants of M. grisea (Xu and Hamer 1996), chkl mutants of C. heterostrophus (Lev et al. 1999), cmkl mutants of C. lagenarium (Takano et al. 2000), and bmpl mutants of $B$. cinerea (Zheng et al. 2000). At present, little is known about

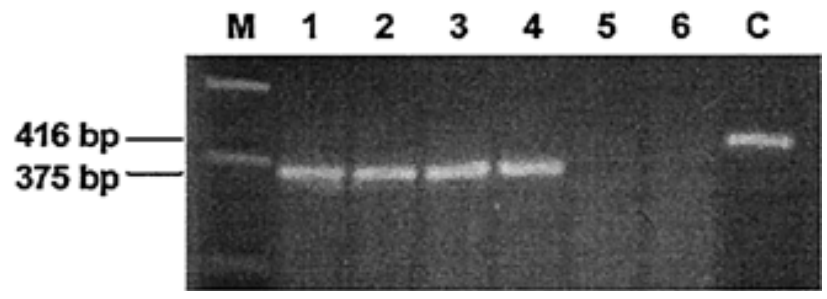

Fig. 2. Reverse transcription-polymerase chain reaction (RT-PCR) products showing expression of PTK1. First-strand cDNAs generated from total RNA isolated from mycelium grown on complete medium (lane 1), conidiophores and conidia formed on peanut leaves-oatmeal agar (lane 2), infected leaves 3 and 5 days postinoculation (lanes 3 and 4, respectively), and uninoculated leaves (lanes 5 and 6) were used as templates for PCR with the gene-specific primers R5 and F6. Lane M, 100-bp ladder marker. Lane C, PCR with genomic DNA as template was performed as a control. 
invasive growth inside plants in fungal pathogens. Thus, studies of fungal genes expressed differentially during this development stage could give clues about the involvement of MAPKs in pathogenicity.

The multiple phenotype shown by $p t k 1$ mutants (deficiency in conidiophore differentiation and conidiation, appressorium formation, and pathogenicity and invasive growth in barley leaves) may indicate that the gene is involved in different pathways, each responsive to different extracellular signals. In this case, specific responses could be achieved by additional related components or pathways. Various sets of phenotypes were found in fungi carrying mutations on different MAPK genes (Table 1). The findings in several phytopathogenic fungi emphasize the different functions of similar signaling MAPK pathways in closely related ascomycete foliar pathogens, even though all of them play crucial roles in fungal pathogenesis.

Appressoria are thought to be required by fungi to invade plants (Emmett and Parbery 1975), although their function

A

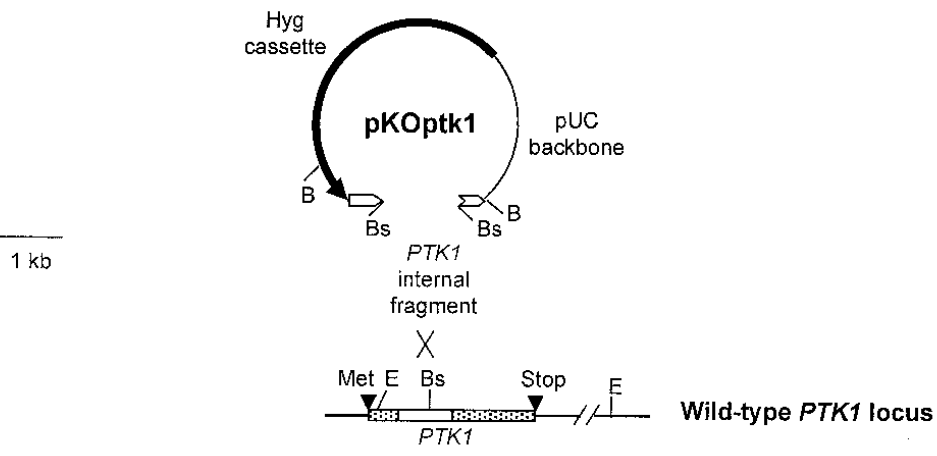

A1

\section{A2}
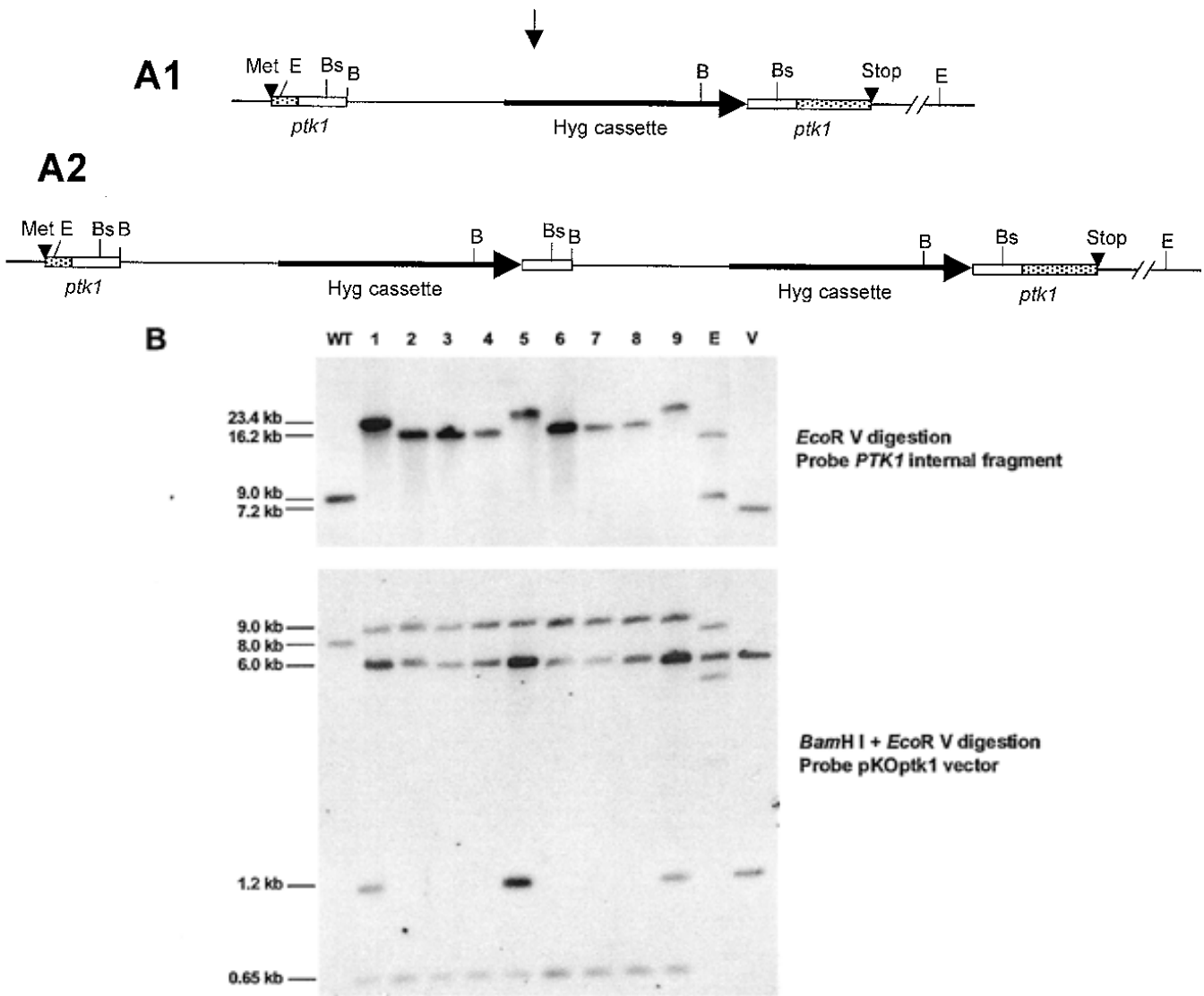

Fig. 3. Disruption of Pyrenophora teres PTK1 gene. A, Disruption vector pKOptk1 and the PTK1 locus. Vector pKOptk1 was constructed by cloning an internal 416-bp fragment of the PTK1 gene (white bar) into the pAN7-1 vector (Punt et al. 1987) next to the hygromycin B resistance gene HPH (black arrow). The vector was linearized at the unique BssHII restriction site located in the PTK1 internal fragment. By homologous recombination through a single crossover, the gene was interrupted by a single-copy insertion event (A1; ptk1 mutants 2, 3, 4, 6, 7, and 8) or by tandem insertion of two copies (A2; ptk1 mutants 1, 5, and 9). Restriction enzyme sites: B = BamHI; Bs = BssHII; E = EcoRV. Methionine and stop codons are indicated by inverted black triangles. The position of a EcoRV restriction site that is $9 \mathrm{~kb}$ away from the EcoRV restriction site located in the coding region of the gene is indicated by a broken line. B, Southern blot analysis of genomic DNA from the wild-type strain (WT), ptk1 mutants (1 to 9), and one ectopic integration transformant (E). Disruption vector pKOptk1 was included as control (V). DNA was digested with EcoRV (upper panel) or with EcoRV and BamHI (lower panel). Blot was probed with the 416-bp internal fragment of the PTK1 gene contained in the disruption vector (white bar; upper panel) or the complete pKOptk1 vector (lower panel). 
may vary among fungi. $M$. grisea and $C$. lagenarium produce large and heavily melanized appressoria that enable them to generate a high, turgor-based pressure and penetrate into their hosts (Chida and Sisler 1987; Chumley and Valent 1990; Howard and Valent 1996; Kawamura et al. 1997; Kubo et al. 1991; Money and Howard 1996; Perpetua et al. 1996). In both fungi, mutants affected in melanin production or defective in appressorium formation are nonpathogenic as a result of their inability to penetrate the plant epidermis (Takano et al. 2000; $\mathrm{Xu}$ and Hamer 1996). Appressoria from Cochliobolus and Alternaria species are smaller, often swelling structures and nonmelanized. In both cases, albino mutants are fully virulent (Guillen et al. 1994; Kubo et al. 1989; Tanabe et al. 1995), as in the case of the albino mutant of P. teres (Lösch and Schäfer, unpublished results). In addition, G $\alpha$-deficient mutants of $C$. heterostrophus that have a severe reduction in the ability to form appressoria, are fully virulent (Horwitz et al. 1999). It has been suggested that small nonmelanized appressoria cannot generate mechanical force sufficient for infection and may not be critical for infection by $C$. heterostrophus. Fungi producing this type of appressoria also may depend on other mechanisms, e.g., enzymatic action, to gain entry into their hosts (Horwitz et al. 1999). Our data seem to be in contrast with those obtained in $C$. heterostrophus because $p t k 1$ mutants cannot produce the small nonmelanized appressoria made by the wild-type strain and are no longer pathogenic. It is possible that appressorium formation in $P$. teres is necessary as a developmental step before colonization of the host tissue, and if this step does not take place, colonization will not occur. This would explain why wounded barley leaves are not infected by the ptkl mutants. It is also possible that PTK1 regulates genes that are directly necessary for appressorium formation and a different set of genes necessary for colonization of the host tissue. Because the role of the small nonmelanized appressoria during the infection process is not clear, the question remains whether the loss of pathogenicity in the ptkl mutants is a result of their inability to form appressoria. The MAPK mutants of $P$. teres should enable us to identify and study downstream components of the Ptk1 MAPK cascade in order to understand the relationship between the fungal signaling pathway, its involvement in conidiation and appressorium formation, and its pathogenicity on barley.

\section{MATERIALS AND METHODS}

\section{Fungal strains and culture conditions.}

$P$. teres strain $15 \mathrm{~A}$ causing the net-type symptoms typical of the net blotch of barley (Weiland et al. 1999) was stored as dried mycelium at room temperature or in $30 \%$ glycerol at $-70^{\circ} \mathrm{C}$. The pathotype of the isolate was periodically confirmed by plant infection assays in a growth chamber. For extraction of DNA and RNA, mycelium was obtained from cultures grown in CM (Leach et al. 1982) in Erlenmeyer flasks on a rotary shaker at $150 \mathrm{rpm}$ and $28^{\circ} \mathrm{C}$. Five-day-old mycelium was harvested and blended with a commercial blender. The resulting homogenates were washed with sterile water, centrifuged, and resuspended in 4 vol of sterile water (wt/vol) and an aliquot transferred to fresh CM and incubated for $14 \mathrm{~h}$. For induction of conidiation, an aliquot of the fungal homogenate was transferred to POA (Speakman and Pommer 1986) and incubated at $18^{\circ} \mathrm{C}$ under near-UV light (TLD 36
W-08; Philips, Eindhoven, The Netherlands) and white light (TL $40 \mathrm{~W}-33 \mathrm{RS}$; Philips) for a 12-h photoperiod for 1 week. The growth rate of the $P$. teres wild-type strain and ptkl mutants was tested on MM (CM agar without yeast extract and casein hydrolysate), CM agar, and under osmotic stress on $\mathrm{CM}$ agar supplemented with varying concentrations of $\mathrm{NaCl}$ $(0.2$ to $1 \mathrm{M})$. In these experiments, plates were inoculated with a 6-mm diameter plug of mycelium and allowed to grow for 12 days at $24^{\circ} \mathrm{C}$. The diameter of the colony was then measured.

\section{Isolation, cloning, and sequencing of PTK1.}

Four degenerate primers were designed on the basis of conserved amino acid regions among different MAPKs: primer 1 (5'-CCAICKIGTNGCIACRTAYTC-3') and primer 4 (5'AYYTCIGGIGCICKRTAVYA-3') were designed on the conserved region of domain VIII; primer 2 (5'-GCITAYGGIRTNGTNTG-3') on the conserved region of domain I; and primer 3 (5'-GTIGCNATRAARAARAT- $\left.3^{\prime}\right)$ on the conserved region of domain II (Hanks and Quinn 1991).

$P$. teres genomic DNA from strain 15A was first amplified with primers 2 and 4 . The $50-\mu$ PCR reaction contained $1.5 \mathrm{mM} \mathrm{MgCl} 2,0.2 \mathrm{mM}$ dNTP (each), 150 pmol of each primer, $100 \mathrm{ng}$ of genomic DNA, $1 \mathrm{U}$ of Taq polymerase, and $1 \times$ PCR buffer (Gibco BRL, Paisley, U.K.). The PCR was initiated by denaturation at $94^{\circ} \mathrm{C}$ for $5 \mathrm{~min}$, followed by 40 cycles at $94^{\circ} \mathrm{C}$ for $1 \mathrm{~min}, 40^{\circ} \mathrm{C}$ for $1 \mathrm{~min}$, and $72^{\circ} \mathrm{C}$ for $1 \mathrm{~min}$. PCR cycling included a final extension step at $72^{\circ} \mathrm{C}$ for 10 min and a cooling step to $4^{\circ} \mathrm{C}$.

After amplification with primers 2 and 4, the PCR reaction was diluted to $1: 50$ and $1 \mu \mathrm{l}$ was used to perform a nested PCR amplification with primers 1 and 3 under the same conditions as described above. A 478-bp PCR fragment was obtained, cloned into pCR 2.1-TOPO vector (Invi-trogen, Leek, The Netherlands), and used as a probe for the screening of a genomic 1EMBL3 library of P. teres strain 15A. Library screening under high-stringency conditions, subcloning, and other routine procedures were performed by standard protocols (Sambook et al. 1989). Sequencing was performed on

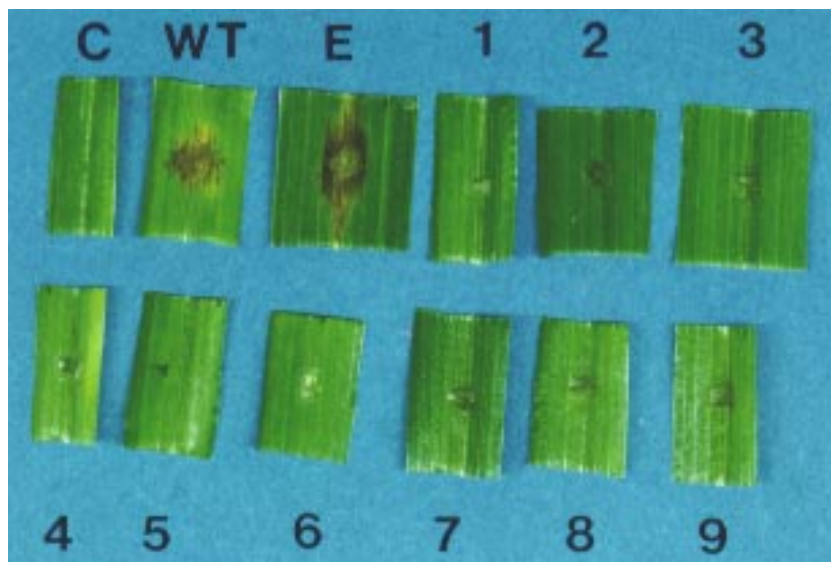

Fig. 4. Pathogenicity assay on barley leaf segments. Intact barley leaf segments were inoculated with the wild-type strain (WT) and nine mutants carrying an interrupted copy of the PTKI gene (1 to 9). Controls consisted of leaf segments inoculated with water (C) as well as leaf segments infected with an ectopic integration transformant (E). Picture was taken 5 days postinoculation. 

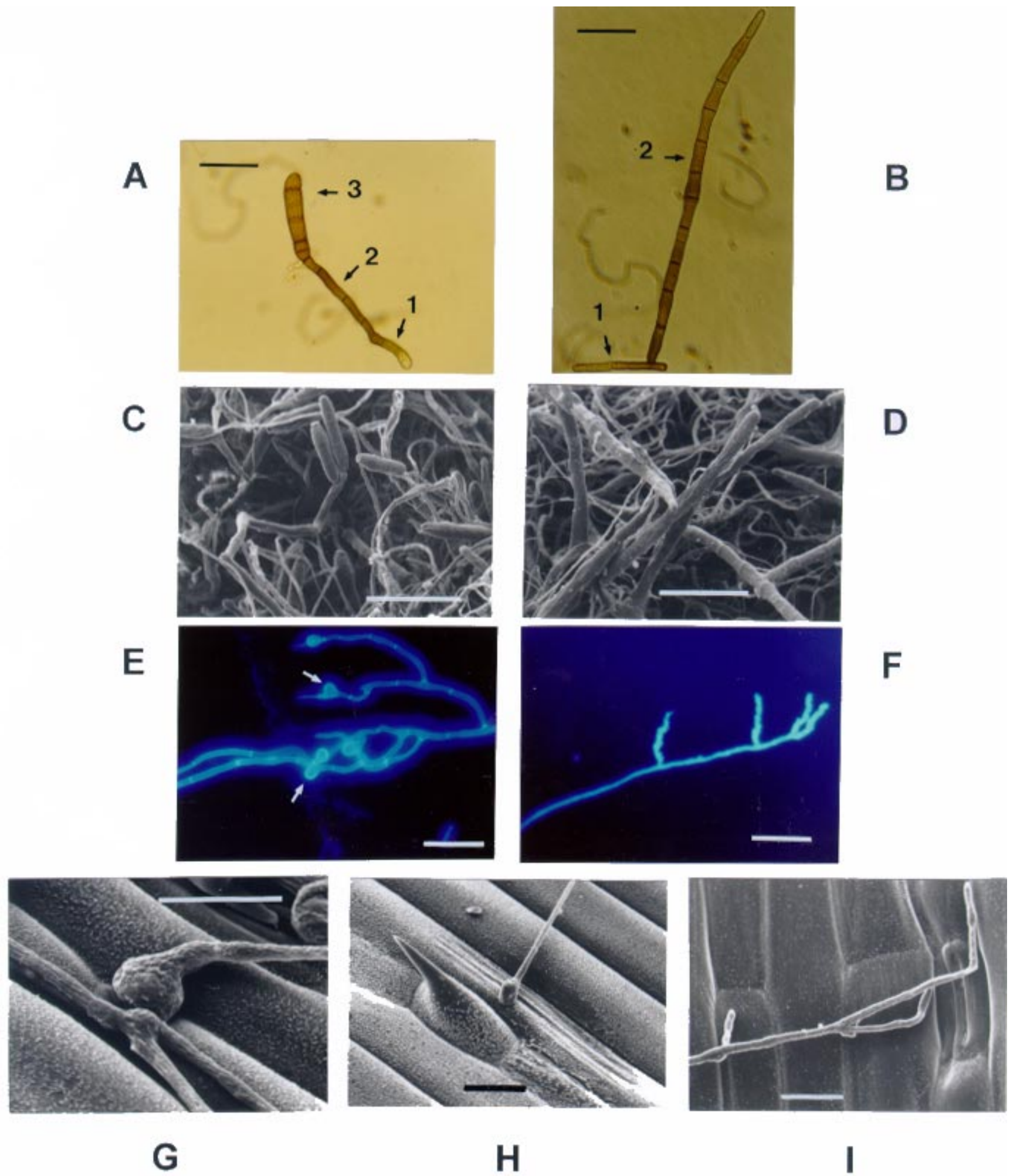

Fig. 5. Effects of targeted disruption of PTK1 on conidiation and appressorium formation. Under conidiation-inducing conditions, conidiophore tips of the wild-type strain differentiate and produce conidia (A and $\mathbf{C})$. Conidiophores from the ptkl mutant strains are approximately three to four times longer than those of the wild-type and do not produce conidia (B and D). A and B, Light microscopy images taken 5 days postinoculation (dpi) on peanut leaves-oatmeal agar $(\mathrm{POA})$ plates $(\mathrm{bar}=50 \mu \mathrm{m} ; 1=$ mycelium; $2=$ conidiophore; $3=$ conidium). $\mathbf{C}$ and $\mathbf{D}$, Scanning electronic micrographs taken 5 dpi on POA plates $(\mathrm{bar}=50 \mu \mathrm{m})$. On a glass surface, wild-type hyphal tips swell to form small appressoria (arrows) (E), whereas mutant strains do not produce appressoria $(\mathbf{F})$. E and F, Fluorescence microscopy images of mycelium stained with calcofluor $24 \mathrm{~h}$ postinoculation $(\mathrm{bar}=50 \mu \mathrm{m})$. On barley leaves, wild-type hyphae form appressoria and penetrate through the cuticle ( $\mathbf{G}$ and $\mathbf{H})$. Hyphae from the mutant strains grow on the leaf surface without developing appressoria, and penetration attempts are not observed (I). G, Bar $=10 \mu \mathrm{m} ; \mathbf{H}$ and I, Bar $=20 \mu \mathrm{m}$. G to I, Scanning electronic microscopy images of infected barley leaves $24 \mathrm{~h}$ postinoculation. 
double-stranded DNA by MWG Sequencing Service (MWGBiotech, Ebersberg, Germany) and AGOWA Sequencing Service (AGOWA GmbH, Berlin, Germany). Sequence data analyses were carried out with the Wisconsin Package, Version 8.3 (Genetics Computer Group, Madison, WI, U.S.A.) and Lasergene Programs (DNAStar, Madison, WI, U.S.A.).

\section{Nucleic acid isolation and analysis.}

Genomic DNA was extracted from $P$. teres mycelium by a DNA Isolation Kit (Gentra Systems, Minneapolis, MN, U.S.A.). Three micrograms of DNA were digested with appropriate enzymes and subjected to Southern hybridization analysis, as described in standard protocols (Sambook et al. 1989), with the use of a nonisotopic DIG-dUTP labeling kit (Boehringer Mannheim, Mannheim, Germany), in accordance with the manufacturer's instructions. Total RNA was prepared according to the protocol of Kay et al. (1987).

\section{Expression studies.}

Expression of the PTK1 gene was carried out by RT-PCR, either in vitro or during infection of barley leaves. Total RNA from $P$. teres strain 15A was extracted from mycelium grown on $\mathrm{CM}$ liquid medium or from conidia and conidiophores harvested from POA plates and used for in vitro growth studies. Barley leaf segments were infected with $P$. teres strain $15 \mathrm{~A}$, and 2 and 5 days postinoculation total RNA was isolated. Leaves inoculated with sterile water were used as control. In order to eliminate possible DNA contaminations, total RNA was treated with DNase I (Life Technologies, Karlsruhe, Germany), according to the manufacturer's instructions. One microgram of total DNA-free RNA was subjected to RT-PCR with the antisense primer R5 5'-ATCCAGAGTTGTCTTCGG TCGA-3' and the sense primer F6 5'-TCCATGTTCTGTCTG AGAACACTACG-3', both flanking the second intron of the gene. RT-PCR was performed with the Access RT-PCR System (Promega Corp., Madison, WI, U.S.A.), following the manufacturer's instructions. First-strand cDNA synthesis was performed at $48^{\circ} \mathrm{C}$ for $45 \mathrm{~min}$ followed by a denaturation step at $94^{\circ} \mathrm{C}$ for $3 \mathrm{~min}$. Second-strand cDNA synthesis and PCR amplification conditions consisted of 40 cycles at $94^{\circ} \mathrm{C}$ for 1 $\min , 59^{\circ} \mathrm{C}$ for $1 \mathrm{~min}$, and $68^{\circ} \mathrm{C}$ for $1 \mathrm{~min}$. PCR cycling included a final extension step at $68^{\circ} \mathrm{C}$ for $7 \mathrm{~min}$ and a cooling step to $4^{\circ} \mathrm{C}$. Aliquots of the PCR products were analyzed on $2.5 \%$ agarose gels. The amplified fragments were cloned into the pGEM-T vector (Promega, Mannheim, Germany) and sequenced in order to confirm their identity.

Transcript analysis of the ptkl mutant strains was also carried out by RT-PCR with the PTK1-specific antisense primer R8 5'-CAGAGATCGGATGTACTCGCG-3' and the sense primer F7 5'-CAATGTCTCCGAGCAGTACGATATC-3', located at the $3^{\prime}$ and $5^{\prime}$ coding region of the gene, respectively. Total RNA was extracted from 5-day-old mycelium grown on CM liquid medium. Control reactions were performed with total RNA from the wild-type strain grown under the same conditions. The RT-PCR reactions were performed under the same conditions as described above. Aliquots of the PCR products were analyzed on $2.5 \%$ agarose gels.

\section{Transformation-mediated gene disruption.}

A 416-bp internal fragment from the PTK1 gene was amplified with the gene-specific primers R5-H 5'-CCCAAGCTT-
GGGATCCAGAGTTGTCTTCGGTCGA-3' and F6-H 5'CCCAAGCTTGGGTCCATGTTCTGTCTGAGAACACTAC G-3', both containing a HindIII restriction site. The $50 \mu \mathrm{l}$ of PCR reaction contained $1.5 \mathrm{mM} \mathrm{MgCl}_{2}, 0.2 \mathrm{mM}$ dNTP (each), 20 pmol of each primer, 20 ng of DNA from pPTK1$5.5 \mathrm{H}, 1 \mathrm{U}$ of Taq polymerase, and 1× PCR buffer (Life Technologies). The PCR was initiated by denaturation at $94^{\circ} \mathrm{C}$ for $5 \mathrm{~min}$, followed by 30 cycles at $94^{\circ} \mathrm{C}$ for $1 \mathrm{~min}, 59^{\circ} \mathrm{C}$ for 1 min, and $72^{\circ} \mathrm{C}$ for $1 \mathrm{~min}$. PCR cycling included a final extension step at $72^{\circ} \mathrm{C}$ for $10 \mathrm{~min}$ and a cooling step to $4^{\circ} \mathrm{C}$. The 416-bp fragment obtained was treated with HindIII and cloned into the unique HindIII restriction site of vector pAN7-1 (Punt et al. 1987) containing the hygromycin-resistant gene $H P H$ as selective marker (Fig. 3A). The resulting plasmid, pKOptk1, was linearized at the unique $B s s \mathrm{HII}$ restriction site located in the PTK1 internal fragment. This linearized construction was used to transform protoplasts of $P$. teres strain 15A.

Protoplast formation was achieved by treating $6 \mathrm{~g}$ of fresh mycelium with $4 \mathrm{ml}(\mathrm{vol} / \mathrm{wt})$ of $5 \%$ driselase enzyme solution per g (InterSpex Products, San Mateo, CA, U.S.A.) in $0.7 \mathrm{M}$ $\mathrm{NaCl}$, with shaking at $100 \mathrm{rpm}$, at $28^{\circ} \mathrm{C}$ for 2 to $3 \mathrm{~h}$. Protoplast solution was then transferred to ice to avoid cell wall regeneration and filtered twice, first through a double-sterile gauze and then through a nylon membrane (cutoff $50 \mu \mathrm{m}$ ). In order to remove the remaining enzyme, protoplasts were washed three times with $0.7 \mathrm{M} \mathrm{NaCl}$ and centrifuged at 3,000 rpm for $10 \mathrm{~min}$ at $4^{\circ} \mathrm{C}$. Finally, they were resuspended in $1 \mathrm{ml}$ of solution Sorb-TC (1.2 M Sorbitol; $50 \mathrm{mM} \mathrm{CaCl} 2$; and $10 \mathrm{mM}$ Tris- $\mathrm{HCl}, \mathrm{pH}$ 7.0). Protoplasts $\left(10^{7}\right)$ were heatshocked at $48^{\circ} \mathrm{C}$ for $5 \mathrm{~min}$ before adding $20 \mu \mathrm{g}$ of transforming DNA in a final volume of $200 \mu \mathrm{l}$. After $10 \mathrm{~min}$ of incubation on ice, 1 vol of polyethylene glycol (PEG)-TC (60\% PEG 4,000; $50 \mathrm{mM} \mathrm{CaCl}_{2}$; and $10 \mathrm{mM}$ Tris-HCl, $\mathrm{pH} \mathrm{7.0)} \mathrm{was}$ added. Ice incubation was extended for an additional $15 \mathrm{~min}$, followed by the addition of $8 \mathrm{vol}$ of PEG-TC. These transformed protoplasts were added to $400 \mathrm{ml}$ of $\mathrm{CM}$ and divided among 20 petri dishes. After 2 days incubation at $24^{\circ} \mathrm{C}$, the regeneration of protoplasts was observed. Petri dishes were then overlaid with $10 \mathrm{ml}$ of hygromycin medium $(1.2 \% \mathrm{wt} / \mathrm{vol}$ agar in water containing $225 \mu \mathrm{g}$ of hygromycin B per ml) (DUCHEFA, Haarlem, The Netherlands). The incubation continued at $24^{\circ} \mathrm{C}$ until hygromycin-resistant transformants appeared.

\section{Pathogenicity tests.}

The barley cultivar Hazera (Steffenson and Webster 1992b) was used for all virulence assays. Plants were grown in $11-\mathrm{cm}$ pots at $16^{\circ} \mathrm{C}$ with a 16 -h photoperiod $(7,500 \times$ at pot level) and $70 \%$ relative humidity. Five leaf segments (7 cm in length) from 4-week-old barley plants were fixed onto filter paper and placed in a $94-\mathrm{mm}$ petri dish with $10 \mathrm{ml}$ of water. Five-dayold mycelium was harvested from $\mathrm{CM}$ liquid cultures and blended with a commercial blender. The resulting homogenates were washed with sterile water, centrifuged, and resuspended in 4 vol of sterile water (wt/vol). Each leaf segment was inoculated with a $50-\mu \mathrm{l}$ drop of the fungal homogenate and incubated at plant culture conditions for 1 week. Full disease symptoms became apparent 4 to 7 days after inoculation. Wounded barley leaves were used to check the ability of the fungus to colonize host tissues. Wounds were produced by abrading the leaf surface with white quartz sand (Sigma- 
Aldrich, Deisenhofen, Germany). Each experiment was independently repeated at least four times. Control samples consisted of intact or wounded leaf segments inoculated with a $50-\mu l$ drop of sterile water.

\section{In vitro and in vivo assays for appressorium formation.}

In order to assess the ability of the fungus to produce appressoria in vitro, 5-day-old mycelia from the wild-type strain, one ectopic integration mutant, and the ptkl mutants were harvested from CM liquid cultures and blended with a commercial blender. The resulting homogenates were washed with sterile water, centrifuged, and resuspended in 4 vol of sterile water (wt/vol). A 100- $\mu$ l aliquot of the homogenate was diluted in $400 \mu \mathrm{l}$ of fresh CM or in CM supplemented with exogenous $10 \mathrm{mM}$ cAMP and transferred to sterile glass slides. The slides were incubated in petri dishes lined with moist filter paper and covered and sealed with Parafilm in a growth chamber at $16^{\circ} \mathrm{C}$ with a 16 -h photoperiod and $70 \%$ relative humidity. Twenty-four hours postinoculation, samples were stained with $10 \mu \mathrm{g}$ of calcofluor per $\mathrm{ml}$ and appressorium formation was checked by fluorescence microscopy.

Appressorium formation was also tested during the infection process. Barley leaves were inoculated with aliquots of fungal homogenates from the wild-type strain and the ptkl mutants with sterile cotton buds that had been immersed in the corresponding homogenate. Twenty-four hours after infection, samples were collected and appressorium formation was checked by scanning electronic microscopy.

\section{ACKNOWLEDGMENTS}

We are grateful to K. Dehn for her help with the scanning electron microscopy and to $\mathrm{B}$. Witt for her critical reading of the manuscript. Pyrenophora teres strain 15A and seeds of barley cultivar Hazera were generously provided by B. J. Steffenson. This work was supported by the EU TMR Network CEREPAT (ERBFMRXCT 980241).

\section{LITERATURE CITED}

Alonso-Monge, R., Navarro-Garcia, F., Molero, G., Diez-Orejas, R., Gustin, M., Pla, J., Sanchez, M., and Nombela, C. 1999. Role of the mitogen-activated protein kinase Hog $1 \mathrm{p}$ in morphogenesis and virulence of Candida albicans. J. Bacteriol. 181:3058-3068.

Brewster, J. L., De Valoir, T., Dwyer, N. D., Winter, E., and Gustin, M. C. 1993. An osmosensing signal transduction pathway in Yeast. Science 259:1760-1763.

Bussink, H.-J., and Osmani, S. A. 1999. A mitogen-activated protein kinase (MPKA) is involved in polarized growth in the filamentous fungus Aspergillus nidulans. FEMS Microbiol. Lett. 173:117-125.

Chida, T., and Sisler, H. D. 1987. Effect of inhibitors of melanin biosynthesis on appressorial penetration and reductive reactions in Pyricularia oryzae and Pyricularia grisea. Pestic. Biochem. Physiol. 29:244-251.

Chumley, F. G., and Valent, B. 1990. Genetic analysis of melanindeficient, nonpathogenic mutants of Magnaporthe grisea. Mol. PlantMicrobe Interact. 3:135-143.

Courchesne, W. E., Kunisawa, R., and Thorner, J. 1989. A putative protein kinase overcomes pheromone-induced arrest of cell cycling in $S$. cerevisiae. Cell 58:1107-1119.

Dixon, K. P., Xu, J.-R., Smirnoff, N., and Talbot, N. J. 1999. Independent signaling pathways regulate cellular turgor during hyperosmotic stress and appressorium-mediated plant infection by Magnaporthe grisea. Plant Cell 11:2045-2058.

Douiyssi, A., Rasmusson, D. C., and Roelfs, A. P. 1998. Responses of barley cultivars and lines to isolates of Pyrenophora teres. Plant Dis. 82:316-321.
Elion, E. A., Grisafi, P. L., and Fink, G. R. 1990. FUS3 encodes a $\mathrm{cdc} 2^{+} / \mathrm{CDC} 28$-related kinase required for the transition from mitosis into conjugation. Cell 60:649-664.

Emmett, R. W., and Parbery, D. G. 1975. Appressoria. Annu. Rev. Phytopathol. 13:147-167.

Gilbert, R. D., and Dean, R. A. 1996. Chemical signals responsible for appressorium formation in the rice blast fungus Magnaporthe grisea. Physiol. Mol. Plant Pathol. 48:335-346.

Gotoh, Y., Nishida, E., Shimanuki, M., Toda, T., Imai, Y., and Yamamoto, M. 1993. Schizosaccharomyces pombe Spk1 is a tyrosinephosphorylated protein functionally related to Xenopus mitogenactivated protein kinase. Mol. Cell. Biol. 13:6427-6434.

Guillen, A., Turgeon, B. G., Thorson, P. R., Bronson, C. R., and Yoder, O. C. 1994. Linkage among melanin biosynthetic mutations in Cochliobolus heterostrophus. Fungal Genet. Newsl. 41:41-42.

Hanks, S. K., and Quinn, A. M. 1991. Protein kinase catalytic domain sequence database: Identification of conserved features of primary structure and classification of family members. Methods Enzymol. 200:38-62.

Harrabi, M., and Kamel, A. 1990. Virulence spectrum to barley in some isolates of Pyrenophora teres from the Mediterranean region. Plant Dis. 74:230-232.

Hoch, H. C., Staples, R. C., Whitehead, B., Comeau, J., and Wolfe, E. D. 1987. Signaling for growth orientation and cell differentiation by surface topography in Uromyces. Science 234:1659-1662.

Horwitz, B. A., Sharon, A., Lu, S.-W., Ritter, V., Sandrock, T. M., Yoder, O. C., and Turgeon, B. G. 1999. A G protein alpha subunit from Cochliobolus heterostrophus involved in mating and appressorium formation. Fungal Genet. Biol. 26:19-32.

Howard, R. J., and Valent, B. 1996. Breaking and entering: Host penetration by the fungal rice blast pathogen Magnaporthe grisea. Annu. Rev. Microbiol. 50:491-512.

Hunter, T. 1995. Protein kinases and phosphatases: The ying and yang of protein phosphorylation and signalling. Cell 80:225-236.

Iwaki, T., Tamai, Y., and Watanable, Y. 1999. Two putative kinase genes, ZrHOG1 and ZrHOG2, cloned from the salt-tolerant yeast Zygosaccharomyces rouxii are functionally homologous to the Saccharomyces cerevisiae HOG1 gene. Microbiology 145:241-248.

Kawamura, C., Moriwaki, J., Kimura, N., Fujita, Y., Fuji, S.-I., Hirano, T., Koizumi, S., and Tsuge, T. 1997. The melanin biosynthesis genes of Alternaria alternata can restore pathogenicity of the melanindeficient mutants of Magnaporthe grisea. Mol. Plant-Microbe Interact. 10:446-453.

Kay, R., Chan, A., Daly, M., and MacPherson, J. 1987. Duplication of CaMV 35S-promotor sequences creates a strong enhancer for plant genes. Science 236:1299-1302.

Keon, J. P. R., and Hargreaves, J. A. 1983. A cytological study of the net blotch disease of barley caused by Pyrenophora teres. Physiol. Plant Pathol. 22:321-329.

Krisak, L., Strich, R., Winters, R. S., Hall, J. P., Mallory, M. J., Kreitzer, D., Tuan, R. S., and Winter, E. 1994. SMK1, a developmentally regulated MAP kinase, is required for spore wall assembly in Saccharomyces cerevisiae. Genes Dev. 8:2151-2161.

Kubo, Y., Tsuda, M., Furusawa, I., and Shishiyama, J. 1989. Genetic analysis of genes involved in melanin biosynthesis of Cochliobolus miyabeanus. Exp. Mycol. 13:77-84.

Kubo, Y., Nakamura, H., Kobayashi, K., Okuno, T., and Furusawa, I. 1991. Cloning of a melanin biosynthetic gene essential for appressorial penetration of Colletotrichum lagenarium. Mol. Plant-Microbe Interact. 4:440-445.

Kültz, D. 1998. Phylogenetic and functional classification of mitogenand stress-activated protein kinases. J. Mol. Evol. 46:571-588.

Leach, J., Lang, B. R., and Yoder, O. C. 1982. Methods for selection of mutants and in vitro culture of Cochliobolus heterostrophus. J. Gen. Microbiol. 128:1719-1729.

Lee, Y.-H., and Dean, R. A. 1994. Hydrophobicity of contact surface induces appressorium formation in Magnaporthe grisea. FEMS Microbiol. Lett. 115:71-76.

Lev, S., Sharon, A., Hadar, R., Ma, H., and Horwitz, B. A. 1999. A mitogen-activated protein kinase of the corn leaf pathogen Cochliobolus heterostrophus is involved in conidiation, appressorium formation and pathogenicity: Diverse roles for mitogen-activated protein kinase homologs in foliar pathogens. Proc. Natl. Acad. Sci. USA 96:1354213547 . 
Li, D., Rogers, L,. and Kolattukudy, P. E. 1997. Cloning and expression of cDNA encoding a mitogen-activated protein kinase from a phytopathogenic filamentous fungus. Gene 195:161-166.

Mayorga, M. E., and Gold, S. E. 1999. A MAP kinase encoded by the $u b c 3$ gene of Ustilago maydis is required for filamentous growth and full virulence. Mol. Microbiol. 34:485-497.

Money, N. P., and Howard, R. J. 1996. Confirmation of a link between fungal pigmentation, turgor pressure, and pathogenicity using a new method of turgor measurement. Fungal Genet. Biol. 20:217-227.

Müller, P., Aichinger, C., Feldbrügge, M., and Kahmann, R. 1999. The MAP kinase Kpp2 regulates mating and pathogenic development in Ustilago maydis. Mol. Microbiol. 34:1007-1017.

Navarro-Garcia, F., Sanchez, M., Pla, J., and Nombela, C. 1995. Functional characterization of the $M K C 1$ gene of Candida albicans, which encodes a mitogen-activated protein kinase homolog related to cell integrity. Mol. Cell Biol. 15:2197-2206.

Perpetua, N. S., Kubo, Y., Yasuda, N., Takano, Y., and Furusawa, I. 1996. Cloning and characterization of a melanin biosynthetic THRI reductase gene essential for appressorial penetration of Colletotrichum lagenarium. Mol. Plant-Microbe Interact. 9:323-329.

Podila, G. K., Rogers, L. M., and Kolattukudy, P. E. 1993. Chemical signals from avocado surface wax trigger germination and appressorium formation in Colletotrichum gloeosporioides. Plant Physiol. 103:267-272.

Punt, P. J., Oliver, R. P., Dingemanse, M. A., Pouwels, P. H., and Van den Hondel, C. A. M. J. J. 1987. Transformation of Aspergillus based on the hygromycin B resistance marker from Escherichia coli. Gene 56:117-124.

Robinson, J., and Jalli, M. 1996. Diversity among Finnish net blotch isolates and resistance in barley. Euphytica 92:81-87.

Sambrook, J., Fritsch, E. F., and Maniatis, T. 1989. Molecular Cloning: A Laboratory Manual, 2nd ed. Cold Spring Harbor Laboratory, Cold Spring Harbor, NY, U.S.A.

San Jose, C., Alonso Monge, R., Perez-Diaz, R., Pla, J., and Nombela, C. 1996. The mitogen-activated protein kinase homolog HOG1 gene controls glycerol accumulation in the pathogenic fungus Candida albicans. J. Bacteriol. 178:5850-5852.

Speakman, J. B., and Pommer, E. H. 1986. A simple method for producing large volumes of Pyrenophora teres spore suspension. Bull.
Br. Mycol. Soc. 20:129-130.

Steffenson, B. J., and Webster, R. K. 1992a. Pathotype diversity of $P y$ renophora teres $\mathrm{f}$. teres on barley. Phytopathology 82:170-177.

Steffenson, B. J., and Webster, R. K. 1992b. Quantitative resistance to Pyrenophora teres f. teres in barley. Phytopathology 82:407-411.

Takano, Y., Kikuchi, T., Kubo, Y., Hamer, J. E., Mise, K., and Furusawa, I. 1999. The Colletotrichum lagenarium MAP kinase gene CMK1 regulates diverse aspects of fungal pathogenesis. Mol. Plant-Microbe Interact. 13:374-383.

Thompson, J. D., Higgins, D. G., and Gibson, T. J. 1994. CLUSTAL W: Improving the sensitivity of progressive multiple sequence alignment through sequence weighting, position-specific gap penalties and weight matrix choice. Nucleic Acids Res. 22:4673-4680.

Toda, T., Dhut, S., Superti-Furga, G., Gotoh, Y., Nishida, E., Sugiura, R., and Kuno, T. 1996. The fission yeast $p m k 1^{+}$gene encodes a novel mitogen-activated protein kinase homolog which regulates cell integrity and functions coordinately with the protein kinase $\mathrm{C}$ pathway. Mol. Cell. Biol. 16:6752-6764.

Torres, L., Martin, H., Garcia-Saez, M. I., Arroyo, J., Molina, M., Sanchez, M., and Nombela, C. 1991. A protein kinase gene complements the lytic phenotype of Saccharomyces cerevisiae lyt 2 mutants. Mol. Microbiol. 5:2845-2854.

Uchiyama, T., and Okuyama K. 1990. Participation of Oryza sativa leaf wax in appressorium formation by Pyricularia oryzae. Phytochemistry 29:91-92.

Weiland, J. J., Steffenson, B. J., Cartwright, R. D., and Webster, R. K. 1999. Identification of molecular genetic markers in Pyrenophora teres f. teres associated with low virulence on 'Harbin' barley. Phytopathology 89:176-181.

$\mathrm{Xu}$, J.-R., and Hamer, J. E. 1996. MAP kinase and cAMP signaling regulate infection structure formation and pathogenic growth in the rice blast fungus Magnaporthe grisea. Genes Dev. 10:2696-2706.

Xu, J.-R., Staiger, C. J., and Hamer, J. E. 1998. Inactivation of the mitogen-activated protein kinase Mps1 from the rice blast fungus prevents penetration of host cells but allows activation of plant defense responses. Proc. Natl. Acad. Sci. USA 95:12713-12718.

Zheng, L., Campbell, M., Murphy, J., Lam, S., and Xu, J.-R. 2000. The $B M P 1$ gene is essential for pathogenicity in the gray mold fungus Botrytis cinerea. Mol. Plant-Microbe Interact. 13:724-732. 